\title{
Evidence for a Causal Contribution of Macaque Vestibular, But Not Intraparietal, Cortex to Heading Perception
}

\author{
Aihua Chen, ${ }^{1}$ Yong Gu, ${ }^{2}$ Sheng Liu, ${ }^{4}$ Gregory C. DeAngelis, ${ }^{3 *}$ and Dora E. Angelaki ${ }^{4 *}$ \\ ${ }^{1}$ Key Laboratory of Brain Functional Genomics (Ministry of Education \& Science and Technology Commission of Shanghai Municipality), School of Life \\ Sciences, East China Normal University, Shanghai 200062, China, ${ }^{2}$ Institute of Neuroscience, Chinese Academy of Sciences, Shanghai 200031, China, \\ ${ }^{3}$ Department of Brain and Cognitive Sciences, Center for Visual Science, University of Rochester, Rochester, New York 14627, and ${ }^{4}$ Department of \\ Neuroscience, Baylor College of Medicine, Houston, Texas 77030
}

Multisensory convergence of visual and vestibular signals has been observed within a network of cortical areas involved in representing heading. Vestibular-dominant heading tuning has been found in the macaque parietoinsular vestibular cortex (PIVC) and the adjacent visual posterior sylvian (VPS) area, whereas relatively balanced visual/vestibular tuning was encountered in the ventral intraparietal (VIP) area and visual-dominant tuning was found in the dorsal medial superior temporal (MSTd) area. Although the respective functional roles of these areas remain unclear, perceptual deficits in heading discrimination following reversible chemical inactivation of area MSTd area suggested that areas with vestibular-dominant heading tuning also contribute to behavior. To explore the roles of other areas in heading perception, muscimol injections were used to reversibly inactivate either the PIVC or the VIP area bilaterally in macaques. Inactivation of the anterior PIVC increased psychophysical thresholds when heading judgments were based on either optic flow or vestibular cues, although effects were stronger for vestibular stimuli. All behavioral deficits recovered within $36 \mathrm{~h}$. Visual deficits were larger following inactivation of the posterior portion of the PIVC, likely because these injections encroached upon the VPS area, which contains neurons with optic flow tuning (unlike the PIVC). In contrast, VIP inactivation led to no behavioral deficits, despite the fact that VIP neurons show much stronger choice-related activity than MSTd neurons. These results suggest that the VIP area either provides a parallel and partially redundant pathway for this task, or does not participate in heading discrimination. In contrast, the PIVC/VPS area, along with the MSTd area, make causal contributions to heading perception based on either vestibular or visual signals.

Key words: heading perception; optic flow; PIVC; reversible chemical inactivation; vestibular; VIP

Significance Statement

Multisensory vestibular and visual signals are found in multiple cortical areas, but their causal contribution to self-motion perception has been previously tested only in the dorsal medial superior temporal (MSTd) area. In these experiments, we show that inactivation of the parietoinsular vestibular cortex (PIVC) also results in causal deficits during heading discrimination for both visual and vestibular cues. In contrast, ventral intraparietal (VIP) area inactivation led to no behavioral deficits, despite the fact that VIP neurons show much stronger choice-related activity than MSTd or PIVC neurons. These results demonstrate that choice-related activity does not always imply a causal role in sensory perception.

\section{Introduction}

Vestibular signals originating from the otolith organs provide a powerful cue for the perception of heading (Telford et al., 1995;

Received June 29, 2015; revised Jan. 25, 2016; accepted Jan. 31, 2016.

Author contributions: G.C.D. and D.E.A. designed research; A.C., Y.G., and S.L. performed research; A.C. and Y.G. analyzed data; A.C., G.C.D., and D.E.A. wrote the paper.

This work was supported by the United States National Institutes of Health Grants DC014518 and DC004260 (to D.E.A.) and EY016178 (to G.C.D.). We thank A. Turner and E. White for monkey care and training.

*G.C.D. and D.E.A. contributed equally to this work.

The authors declare no competing financial interests.

Correspondence should be addressed to Dora Angelaki, Dept. of Neuroscience, Room S740, MS: BCM295, Baylor

College of Medicine, One Baylor Plaza, Houston, TX 77030. E-mail: angelaki@bcm.edu
Ohmi, 1996; Harris et al., 2000; Gu et al., 2007), as do large-field visual motion (optic flow) cues (Gibson, 1950). Neural selectivity for heading has been described extensively in the dorsal medial superior temporal (MSTd) area, where many neurons show heading tuning in response to both inertial motion and optic flow (Duffy, 1998; Bremmer et al., 1999; Gu et al., 2006; Britten, 2008; Fetsch et al., 2010; Angelaki et al., 2011). However, even with multiple bilateral injections of the GABA agonist muscimol, effects of reversible inactivation of the MSTd area on vestibular heading discrimination are relatively weak $(\sim 20 \%)$, compared 
with threefold increases in visual heading thresholds (Gu et al., 2012). Thus, other cortical areas likely contribute to heading perception.

Two such candidate areas are the ventral intraparietal (VIP) area (Schaafsma and Duysens, 1996; Britten and van Wezel, 1998; Bremmer et al., 2002a, b; Britten and Van Wezel, 2002; Schlack et al., 2002; Zhang et al., 2004; Chen et al., 2011c) and the parietoinsular vestibular cortex (PIVC; Grüsser et al., 1990; Chen et al., 2010). Quantitative analysis of vestibular spatiotemporal response properties of MSTd, VIP, and PIVC neurons has suggested a hierarchy of cortical vestibular processing, with the PIVC being most proximal to the vestibular periphery and the MSTd area being most distal (Chen et al., 2011a). In fact, the PIVC receives direct vestibular input from the thalamus (Akbarian et al., 1994). PIVC neurons do not show heading tuning in response to optic flow (Chen et al., 2010), although the most posterior portion of the PIVC merges with the visual posterior sylvian (VPS, also known as T3) area (Jones and Burton, 1976; Guldin et al., 1992; Guldin and Grüsser, 1998; Dicke et al., 2008) and neurons in the VPS area do show moderate selectivity to optic flow (Chen et al., 2011b). Thus, previous work reveals a continuum of visual-vestibular convergence: vestibular-dominant heading tuning is found in the PIVC and the VPS area (Chen et al., 2011b), relatively balanced visual and vestibular tuning is encountered in the VIP area (Chen et al., 2011c), visual-dominant heading tuning is found in the MSTd area (Gu et al., 2006, 2007, 2010), and no vestibular responses to translation are found in the middle temporal (MT) area, which provides visual input to the MSTd and VIP areas (Chowdhury et al., 2009). Simulations revealed that the results of MSTd inactivation could be nicely explained if one or more areas with vestibular-dominant tuning also contribute to heading perception (Gu et al., 2012).

Thus, our goal was to investigate whether either the PIVC or the VIP area makes a causal contribution to heading perception. We did this by manipulating neural activity using reversible chemical inactivation while animals performed a fine heading discrimination task (Gu et al., 2007, 2008, 2012). We found that bilateral inactivation of the anterior PIVC resulted in substantial deficits in vestibular heading perception, whereas inactivation of the posterior PIVC resulted in smaller, but still significant, deficits. In contrast, VIP inactivation led to negligible changes in heading perception based on either visual or vestibular signals. Together, our findings suggest that the PIVC and the VPS area may constitute the vestibular-dominant areas that, combined with signals from the MSTd area, drive multisensory heading perception (Gu et al., 2012). In contrast, the lack of a causal contribution of the VIP area to heading perception, despite the presence of strong choice-related activity during heading discrimination (Chen et al., 2011c, 2013), provides a puzzle for future studies to unravel.

\section{Materials and Methods}

Three male rhesus monkeys (Macaca mulatta), weighing $\sim 6-10 \mathrm{~kg}$, were chronically implanted with a circular molded, lightweight plastic ring for head restraint, a recording grid, and a scleral coil for eye-movement recording (for details, seeGu et al., 2006). After recovery, animals were trained using standard operant conditioning to fixate visual targets for fluid reward, and to report their direction of heading, as described below. All animal surgeries and experimental procedures were approved by the Institutional Animal Care and Use Committee at Baylor College of Medicine and were in accordance with National Institutes of Health guidelines.

Heading discrimination task. Monkeys were trained, using standard operant conditioning techniques, to report their direction of translation during a two-alternative, forced-choice heading discrimination task (Fig. 1). In each trial, the monkey was moved along one of several directions in the horizontal plane (leftward or rightward relative to straight ahead; Fig. $1 A)$, while maintaining fixation $\left(2 \times 2^{\circ}\right.$ electronic window $)$ on a central, head-fixed target (Fig. 1B). Across trials, the heading was varied in fine steps around straight ahead. The range of headings was chosen based on extensive psychophysical testing using a staircase paradigm. Nine logarithmically spaced heading values were tested for each monkey, including an ambiguous straight-ahead direction (Monkey J: $\pm 8^{\circ}, \pm 4^{\circ}, \pm 2^{\circ}, \pm 1^{\circ}$, $0^{\circ}$; Monkey Y: $\pm 9^{\circ}, \pm 3.5^{\circ}, \pm 1.3^{\circ}, \pm 0.5^{\circ}, 0^{\circ}$; Monkey B: $\pm 16^{\circ}, \pm 6.4^{\circ}$, $\left.\pm 3.5^{\circ}, \pm 2.6^{\circ}, \pm 1^{\circ}, 0^{\circ}\right)$. To report their perceived heading, animals were trained to make a saccade to one of two targets that appeared $5^{\circ}$ left and right of the fixation point after termination of the motion stimulus (Fig. $1 B)$. The saccade had to be made within $1 \mathrm{~s}$ of the appearance of the two targets, and the saccade endpoint had to remain within $3^{\circ}$ of the target for $\geq 150 \mathrm{~ms}$ to be considered a valid choice. Correct responses were rewarded with a drop of water or juice. For the ambiguous heading condition $\left(0^{\circ}\right.$, straight ahead), rewards were delivered randomly on half of the trials.

The experimental paradigm consisted of three randomly interleaved stimulus conditions: (1) in the "vestibular" condition, the monkey was translated by a motion platform (Moog 6DOF2000E) while fixating a head-fixed target on a blank screen; (2) in the "visual" condition, the motion platform remained stationary while optic flow simulated the same range of headings; (3) in the "combined" condition, congruent inertial motion and optic flow were provided, with visual and vestibular stimuli being temporally synchronized (for details, see Gu et al., 2006). The motion trajectory was $2 \mathrm{~s}$ in duration and followed a Gaussian velocity profile. The total displacement along the motion trajectory was 30 $\mathrm{cm}$, with a peak acceleration of $\pm 0.1 \times g\left( \pm 0.98 \mathrm{~m} / \mathrm{s}^{2}\right)$ and a peak velocity of $45 \mathrm{~cm} / \mathrm{s}$. These vestibular stimuli are far above perceptual thresholds (MacNeilage et al., 2010). Each stimulus condition was repeated $\geq 10$ times, but more typically 30 times.

Visual stimuli for the visual and combined conditions were generated by a three-chip DLP (Digital Light Processing) projector (Christie Digital Mirage 2000) mounted on the motion platform. This projector rearprojected images (subtending $90 \times 90^{\circ}$ of visual angle) onto a tangent screen located $30 \mathrm{~cm}$ in front of the monkey. Visual stimuli depicted movement through a 3D cloud of "stars" that occupied a virtual space $100 \mathrm{~cm}$ wide, $100 \mathrm{~cm}$ tall, and $50 \mathrm{~cm}$ deep. A near clipping plane prevented stars from being rendered when they were closer than $5 \mathrm{~cm}$ to the animal's eyes. Star density was $0.01 / \mathrm{cm}^{3}$, with each star being a $0.15 \times$ $0.15 \mathrm{~cm}$ triangle. Stimuli were presented stereoscopically as red/green anaglyphs and were viewed through Kodak Wratten filters (red no. 29; green no. 61). The display contained a variety of depth cues, including horizontal disparity, motion parallax, and size information. The binocular disparity of the stars ranged from $32^{\circ}$ crossed (nearest dots at the clipping plane distance of $5 \mathrm{~cm}$ ) to $3^{\circ}$ uncrossed. Thus, our stimuli are well suited to activating VIP neurons, which have been reported to prefer near or ultranear depths (Colby et al., 1993; Yang et al., 2011; Bremmer et al., 2013).

The motion coherence of the visual display was manipulated by randomizing the 3D location of a certain percentage of the stars on each display update while the remaining stars moved according to the specified heading (Gu et al., 2008). This manipulation degrades optic flow as a heading cue and was used to reduce psychophysical sensitivity in the visual condition such that it approximately matched vestibular sensitivity. In the experiments tested here, visual motion coherence was set to 55-84\% (Monkey J, tested for both VIP and PIVC inactivation), 20\% for Monkey Y (PIVC inactivation only), and $\sim 11 \%$ for Monkey B (VIP inactivation only).

Reversible inactivation. The PIVC and the VIP area were localized using a combination of magnetic resonance imaging (MRI) scans, stereotaxic coordinates, white/gray matter transitions, and physiological response properties. For the VIP area, we first identified the medial tip of the intraparietal sulcus and then moved laterally until there was no longer a directionally selective visual response in the multiunit (MU) activity. At the anterior end of the VIP area, visually responsive neurons gave way to purely somatosensory cells in the fundus. At the posterior end, direction- 
A Lateral View

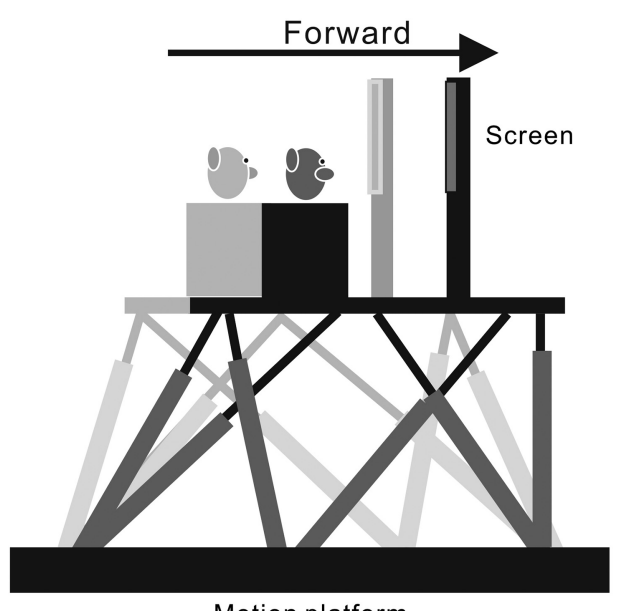

Motion platform

B

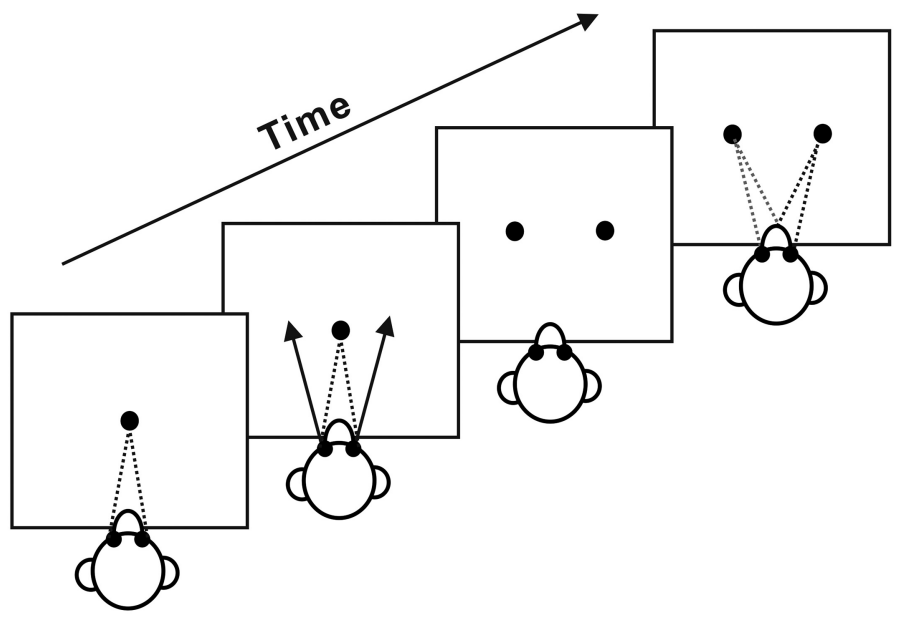

C

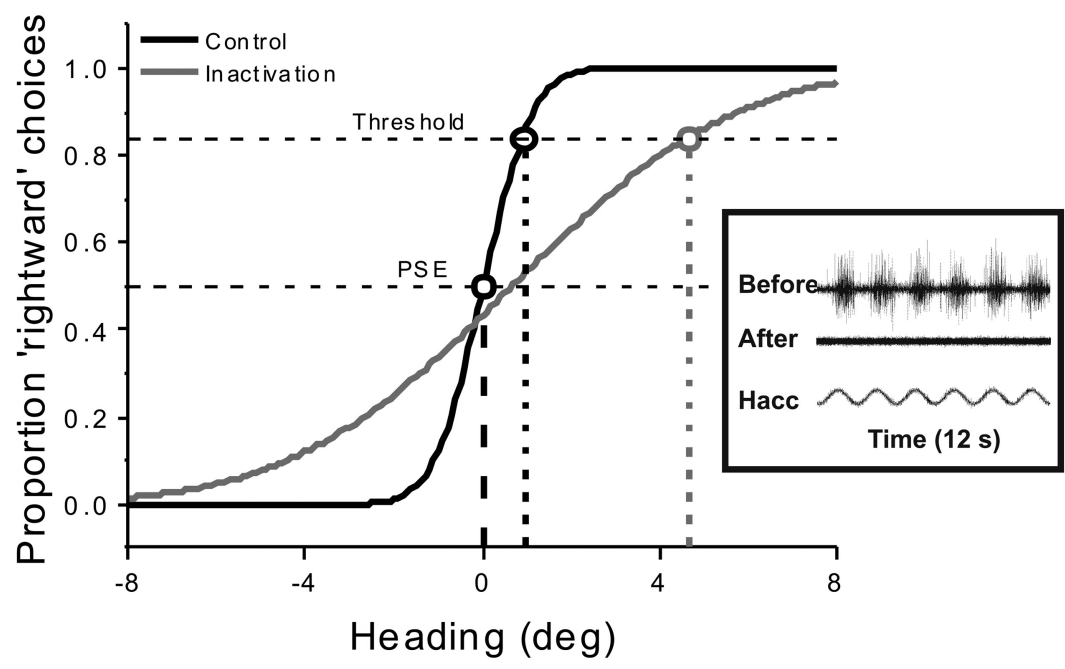

Figure 1. Experimental setup, heading discrimination task, and hypothesized changes in behavioral performance following reversible inactivation. $\boldsymbol{A}$, Using a motion platform, animals were translated forward along different heading directions in the horizontal plane. Positive heading angles correspond to rightward directions and $0^{\circ}$ denotes straight-ahead motion. A projector mounted on the motion platform displayed images of a 3D star field and provided optic flow cues. $\boldsymbol{B}$, Each trial began with the appearance of a small, head-centered fixation target at the center of the display. As soon as motion stimulus was completed, the fixation point disappeared and two choice targets appeared. Monkeys were required to make a saccade to one of the two targets to report their perceived heading as leftward or rightward relative to straight ahead. C, Predicted effects of inactivation on heading discrimination performance. Muscimol injection suppresses neural activity, as illustrated by a 12 s epoch of raw neural activity selective neurons gave way to visual cells that were not selective for motion. For the PIVC, we mapped an extensive region of cortex around the lateral sulcus that extended $15 \mathrm{~mm}$ along the anterior-posterior axis. Vestibular responses were recorded at depths between 11 $\mathrm{mm}$ (at the posterior end) and $17 \mathrm{~mm}$ (at the anterior end) from the surface of the cortex. At the posterior end, the PIVC region was localized lateral to the border between the VIP area and the lateral intraparietal (LIP) area and above the superior temporal gyrus. The most posterior sections of the PIVC were located at anterior-posterior coordinates similar to the vestibular-responsive neurons in the VIP area (Chen et al., 2011c) and anterior to most of the vestibular-responsive neurons in the MSTd area (Gu et al., 2006). The most anterior portions of the PIVC were encountered beneath and lateral to the VIP area. Importantly, both the PIVC and the VIP area were extensively mapped before muscimol injections, and these same animals had been previously used to characterize neuronal responses in these areas (PIVC/VPS: Chen et al., 2010, 2011b; VIP: Chen et al., 2011c, 2013).

Once the areas were thoroughly mapped bilaterally, $\sim 2 \mu \mathrm{l}$ of muscimol (concentration, $10 \mathrm{mg} / \mathrm{ml}$ ) was injected using a "microinjectrode," which consists of a fine tungsten electrode inside a thin cannula (Chen et al., 2001; Chowdhury and DeAngelis, 2008). Muscimol, $\mathrm{a} \mathrm{GABA}_{\mathrm{A}}$ agonist, suppresses neuronal activity by binding to $\mathrm{GABA}_{\mathrm{A}}$ receptors (Arikan et al., 2002; Edeline et al., 2002; Allen et al., 2008; Liu et al., 2010). Further details of our inactivation approach have been described previously ( $\mathrm{Gu}$ et al., 2012). The advantage of this approach is that it allows us to monitor MU activity before and after muscimol injection, such that silencing of neural activity can be confirmed before behavioral testing (Fig. $1 C$, inset).

We inserted the injectrode into the brain through a transdural guide tube oriented vertically within the coronal plane; repeatable positioning of injectrodes was facilitated by a recording grid attached stereotaxically to the cranial implant. MU activity was monitored and response properties were mapped while the injectrode was lowered into the brain. Once the electrode tip (which typically extended $\sim 300-500 \mu \mathrm{m}$ beyond the end of the cannula) entered the target area, it was advanced to a depth of $\sim 700-1000 \mu \mathrm{m}$ below the top of the target area, such that the tip of the cannula was approximately centered in the thickness of the cortex. This helped ensure that the drug spread approximately uniformly to the upper and lower layers of gray matter. Projections of our recording sites onto volumetric MRI images

(inset) measured in the PIVC before and 20 min after injection of muscimol. These traces show responses to a $0.5 \mathrm{~Hz}$ sinusoidal lateral translation. If an area is involved in heading perception, inactivation is expected to deteriorate the precision of heading discrimination, leading to a shallower psychometric function. 
Table 1. Properties of injection sites ${ }^{a}$

\begin{tabular}{|c|c|c|c|c|c|c|}
\hline \multirow[b]{2}{*}{$\begin{array}{l}\text { Area; } \\
\text { Monkey }\end{array}$} & \multicolumn{3}{|l|}{ Left hemisphere } & \multicolumn{3}{|l|}{ Right hemisphere } \\
\hline & $\begin{array}{l}\text { Site 1: anterior-posterior; } \\
\text { medial-lateral; } \\
\text { depth (mm) }\end{array}$ & $\begin{array}{l}\text { Site 2: anterior-posterior; } \\
\text { medial-lateral; } \\
\text { depth (mm) }\end{array}$ & $\begin{array}{l}\text { Distance } \\
(\mathrm{mm})\end{array}$ & $\begin{array}{l}\text { Site 3: anterior-posterior; } \\
\text { medial-lateral; } \\
\text { depth (mm) }\end{array}$ & $\begin{array}{l}\text { Site 4: anterior-posterior; } \\
\text { medial-lateral; } \\
\text { depth (mm) }\end{array}$ & $\begin{array}{l}\begin{array}{l}\text { Distance } \\
(\mathrm{mm})\end{array} \\
\end{array}$ \\
\hline \multirow{5}{*}{ PIVC; J } & $13.05 ;-12.4 ; 15$ & $11.45 ;-11.6 ; 15.1$ & 1.79 & $12.25 ; 15.2 ; 15.6$ & $10.65 ; 15.2 ; 16.2$ & 1.71 \\
\hline & $12.25 ;-11.2 ; 15.04$ & $12.25 ;-12.8 ; 14.28$ & 1.77 & $12.25 ; 16.8 ; 15.3$ & $11.45 ; 14.8 ; 14.5$ & 2.28 \\
\hline & $13.05 ;-11.6 ; 15.2$ & $11.45 ;-11.6 ; 15.2$ & 1.6 & $12.25 ; 16.0 ; 13.2$ & $10.65 ; 15.2 ; 14.8$ & 2.4 \\
\hline & $9.05 ;-13.6 ; 13.7$ & $10.65 ;-12.8 ; 14.0$ & 1.81 & $10.65 ; 16.8 ; 13.8$ & $8.25 ; 17.2 ; 13.9$ & 2.43 \\
\hline & $8.25 ;-14.0 ; 12.4$ & $9.85 ;-12.4 ; 14.8$ & 3.30 & $10.65 ; 17.6 ; 13.6$ & $8.25 ; 18.0 ; 12.6$ & 2.63 \\
\hline \multirow[t]{4}{*}{ PIVC; Y } & $7.05 ;-16.8 ; 10.5$ & $8.646 ;-17.6 ; 11.8$ & 1.97 & $6.246 ; 11.6 ; 8.3$ & $7.846 ; 12.4 ; 9.5$ & 2.15 \\
\hline & $7.85 ;-17.2 ; 10.6$ & $9.446 ;-18.0 ; 11.8$ & 2.15 & $6.246 ; 12.4 ; 10.0$ & $7.846 ; 13.2 ; 10.0$ & 1.79 \\
\hline & $8.65 ;-16.8 ; 10.0$ & $9.446 ;-18.0 ; 10.0$ & 1.44 & $8.646 ; 13.6 ; 10.8$ & $7.046 ; 13.6 ; 9.8$ & 1.89 \\
\hline & $4.65 ;-18.8 ; 8.8$ & $5.446 ;-17.6 ; 9.8$ & 1.75 & $4.646 ; 13.2 ; 9.3$ & $3.846 ; 14.4 ; 9.0$ & 1.47 \\
\hline \multirow{6}{*}{ VIP; J } & $5.05 ;-7.60 ; 13.1$ & $7.45 ;-8.80 ; 11.9$ & 2.94 & $7.45 ; 13.6 ; 12.1$ & $6.65 ; 14.00 ; 12.8$ & 1.14 \\
\hline & $5.05 ;-6.80 ; 13.2$ & $7.45 ;-9.60 ; 12.2$ & 3.82 & $5.05 ; 12.40 ; 12.8$ & $7.45 ; 14.40 ; 12.2$ & 3.18 \\
\hline & $5.05 ;-8.40 ; 11.6$ & $8.25 ;-10.0 ; 10.9$ & 3.64 & $4.25 ; 12.00 ; 13.6$ & 5.05; 13.20; 11.0 & 2.97 \\
\hline & $3.45 ;-8.40 ; 13.4$ & $6.65 ;-7.60 ; 13.0$ & 3.32 & $6.65 ; 14.80 ; 12.2$ & $4.25 ; 12.80 ; 13.7$ & 3.46 \\
\hline & $4.25 ;-8.00 ; 13.4$ & $6.65 ;-9.20 ; 13.0$ & 2.71 & $8.25 ; 14.8 ; 11.4$ & $5.05 ; 13.20 ; 13.5$ & 4.15 \\
\hline & $5.85 ;-7.20 ; 13.4$ & $6.65 ;-10.0 ; 12.0$ & 3.23 & $4.25 ; 10.4 ; 14.5$ & $5.85 ; 13.6 ; 13.0$ & 3.88 \\
\hline \multirow[t]{5}{*}{ VIP; B } & $2.65 ;-10.4 ; 12.2$ & $5.85 ;-11.2 ; 10.6$ & 3.67 & $2.65 ; 9.6 ; 11.2$ & $4.25 ; 10.4 ; 11.0$ & 1.8 \\
\hline & $4.25 ;-12.0 ; 11.2$ & $2.65 ;-12 ; 10.5$ & 1.75 & $4.25 ; 12.0 ; 12.7$ & $2.65 ; 8.8 ; 9.9$ & 4.54 \\
\hline & $1.05 ;-12.0 ; 11.5$ & $2.65 ;-11.2 ; 11.1$ & 1.83 & $5.85 ; 11.2 ; 11.2$ & $2.65 ; 11.2 ; 12.1$ & 3.32 \\
\hline & $2.65 ;-8.8 ; 10.6$ & $4.25 ;-11.2 ; 11.4$ & 2.99 & $1.05 ; 11.2 ; 12.1$ & $2.65 ; 10.4 ; 11.1$ & 2.05 \\
\hline & $2.65 ;-10.4 ; 11.0$ & $5.85 ;-11.2 ; 12.1$ & 3.48 & $4.25 ; 10.4 ; 12.1$ & $2.65 ; 10.4 ; 11.2$ & 1.84 \\
\hline
\end{tabular}

${ }^{a}$ Each row corresponds to one experiment and indicates the location (anterior-posterior and medial-lateral coordinates, as well as estimated depth relative to the dura mater, all in units of millimeters) of each injection, as well as the distance between the pair of injections made in each hemisphere.

(data not shown) indicate that most injections into VIP were made near the fundus of the intraparietal sulcus, although some injections farther away from the fundus may have been more concentrated in the upper or lower banks of the sulcus. As a result, our penetrations were generally not perpendicular to the layers of the cortex. Thus, we mapped out the thickness of cortex at each location in the recording grid using electrode penetrations before inactivation experiments, and we attempted to center injections such that they would affect all layers of cortex.

Once the injectrode was situated, we tested MU activity with $0.5 \mathrm{~Hz}$ sinusoidal lateral translation (for the PIVC; Fig. $1 C$, inset) and/or optic flow stimuli (for the VIP area). If there was a clear audible response modulation, we then ejected $\sim 2 \mu \mathrm{l}$ of muscimol to fill the empty volume of the injectrode. Subsequently, an additional $\sim 2 \mu$ of muscimol was injected very slowly $(0.1 \mu \mathrm{l} / \mathrm{min})$ over $\sim 20 \mathrm{~min}$ to ensure that pressure did not force the drug back up along the path of the cannula (Chowdhury and DeAngelis, 2008). Neural activity was typically silenced by the end of the $20 \mathrm{~min}$ injection period (for details, see Gu et al., 2012), indicating successful delivery of the drug. All data presented here were collected following four bilateral injections of muscimol (two in each hemisphere). For each hemisphere, the two injection sites were typically separated by 2-3 mm (range: 1.14-4.60 mm; Table 1). For the VIP area, the mean separation between a pair of injection sites in the same hemisphere $(3.03 \pm 0.17 \mathrm{~mm}, \mathrm{SEM})$ was significantly greater than the mean separation $(1.99 \pm 0.09 \mathrm{~mm})$ between pairs of injection sites in the PIVC $(p<$ 0.001 , Wilcoxon rank sum test). This was part of an intentional strategy to inactivate a larger portion of the VIP area (see Results), given that effects of muscimol were negative.

Inactivation experiments were conducted on a weekly schedule. Data collected on the first $2 \mathrm{~d}$ (Monday, Tuesday) of each week served as controls [preinjection (Pre)] and was averaged. Muscimol injections were made on Wednesday and behavioral data were then collected immediately after the injections on Wednesday afternoon/evening $(0 \mathrm{~h})$, and again on Thursday morning (12 h) and Friday morning ( $36 \mathrm{~h})$. Consistent with previous studies of the MSTd area using the same con- centration of muscimol (Gu et al., 2012), the effects of the drug always disappeared between the 12 and $36 \mathrm{~h}$ time points. We have previously shown that saline injections into the MSTd area, performed using an identical experimental protocol, did not significantly elevate heading thresholds in any of the stimulus conditions (Gu et al., 2012). Saline controls were not repeated in these experiments.

Reconstruction of inactivation sites. To reconstruct the locations of injection sites, we analyzed MRI images as follows (for details, see Gu et al., 2006; Chen et al., 2010). An initial scan was performed on each monkey before any surgeries using a high-resolution sagittal MPRAGE sequence $(0.75 \times 0.75 \times 0.75 \mathrm{~mm}$ voxels $)$. SureFit software (Van Essen et al., 2001) was used to segment gray matter from white matter. A second scan was performed after the head holder and recording grid had been surgically implanted. Small cannulae filled with a contrast agent (gadoversetamide) were inserted into the recording grid during the second scan to register electrode penetrations with the MRI volume. The MRI data were converted to a flat map using Caret software (Van Essen et al., 2001) and the flat map was morphed to match a standard macaque atlas. The data were then refolded and transferred onto the original MRI volume. Thus MRI images were obtained showing the functional boundaries between different cortical areas, along with the expected trajectories of electrode penetrations through the guide tubes. The locations of the injection sites are shown on MRI flat maps in Figure 2.

To approximately reconstruct the portions of an area that were inactivated by muscimol injections, a spherical region around some injection sites was projected onto the flat maps of Figure 2. Previous work (Arikan et al., 2002; Edeline et al., 2002; Allen et al., 2008; Liu et al., 2010) suggests that muscimol inactivates a region having a radius in the range of 1-3 $\mathrm{mm}$. Given that our injection volumes and drug concentration were substantially larger than those used in these previous studies, our reconstructions assumed that muscimol inactivates a spherical region having a radius of $2 \mathrm{~mm}$. We think this is a reasonable estimate, and may be somewhat conservative, especially given that we also measured effects on behavior on the day following injection. We measured the surface area of 


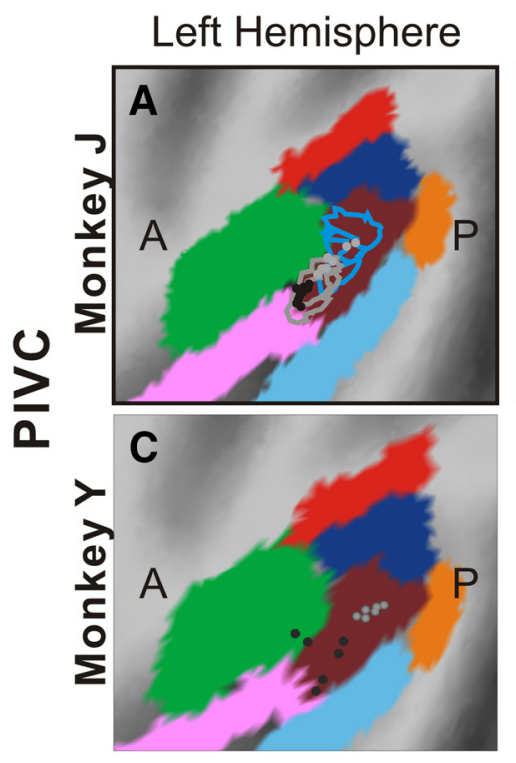

\section{Right Hemispere}
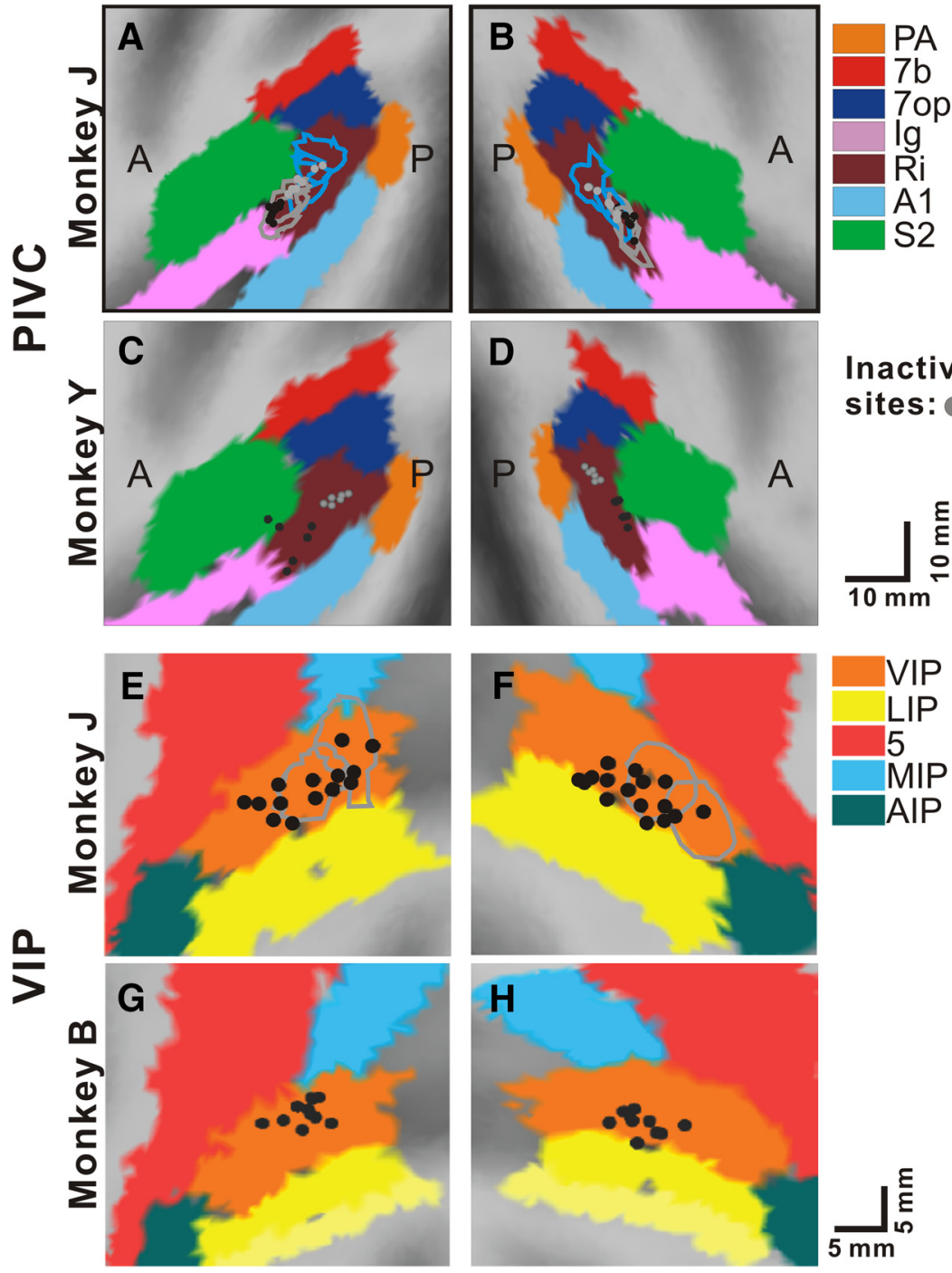

Figure 2. Anatomical localization of inactivation sites. $\boldsymbol{A}-\boldsymbol{D}$, PIVC inactivation sites in Monkeys $J$ and $\mathrm{Y}$, projected onto flat maps of cortex made with Caret software. Black and gray circles in $\mathbf{A}-\boldsymbol{D}$ denote anterior and posterior PIVC injection sites, respectively. Each circle represents one injection site. The gray and cyan boundaries in the flat maps for Monkey J represent estimates of the regions of inactivation corresponding to pairs of muscimol injections in anterior (distance between paired injection sites: $1.96 \mathrm{~mm}$ for left hemisphere, $1.94 \mathrm{~mm}$ for right hemisphere) and posterior (distance between paired injection sites: $2.89 \mathrm{~mm}$ for left hemisphere, $1.79 \mathrm{~mm}$ for right hemisphere) PIVC, respectively. $\boldsymbol{E}-\boldsymbol{H}$, VIP inactivation sites in Monkeys J and B. Gray boundaries for Monkey J again represent estimated regions of inactivation for a pair of VIP injection sites (distance between paired injection sites: $2.71 \mathrm{~mm}$ for left hemisphere, $4.15 \mathrm{~mm}$ for right hemisphere). Each panel shows a lateral view of the 3D surface reconstruction of one hemisphere, with various functional areas denoted by colored regions [from the parcellation scheme of Lewis and Van Essen $(2000 a, b)]$.

the flat-map projections of some sets of injections and divided by the total surface area for each brain region to estimate the proportion of each area that was inactivated by a typical set of injections.

Data analysis. Behavioral performance was quantified by plotting the proportion of "rightward" choices as a function of heading (relative to straight ahead) and psychometric functions were fit with a cumulative Gaussian function as follows:

$$
P(h)=\frac{1}{\sigma \sqrt{2 \pi}} \int_{-\infty}^{h} e^{\frac{-(x-\mu)^{2}}{2 \sigma^{2}}} d x
$$

Psychophysical threshold was defined as the SD of the Gaussian fit, $\sigma$, which corresponds to $84 \%$ correct performance (assuming no bias).
Inactivation sites:
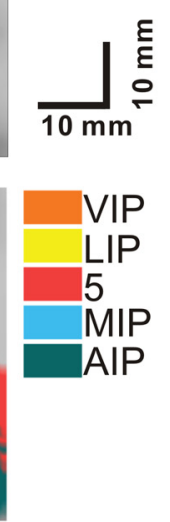

Statistical analysis. All average values are given as means \pm SEM. The criterion for statistical significance was taken to be $p<0.05$. To evaluate the significance of muscimol effects across time points and across animals, a twoway ANOVA (with factors of time point and animal identity) was applied separately for each brain area and each stimulus condition.

\section{Results}

Muscimol inactivation $(\sim 2 \mu \mathrm{l}$ of volume per injection; $10 \mu \mathrm{g} / \mu \mathrm{l}$ concentration) of an area causally linked to heading perception is expected to increase heading discrimination thresholds by flattening the psychometric function (Fig. 1C). All data reported here were collected following four sequential injections of muscimol, two injections in each hemisphere, $\sim 2-3$ $\mathrm{mm}$ apart (see Materials and Methods; Table 1). In pilot experiments in the PIVC, we also made two muscimol injections in only one hemisphere, and did not observe any consistent effects of inactivating the PIVC, as found previously for the MSTd area (Gu et al., 2012). Thus, given that our visual stimuli are full field and that vestibular signals are not lateralized, we made bilateral injections for all subsequent experiments.

For each inactivation experiment, behavioral performance was measured in the vestibular, visual, and combined conditions (randomly interleaved) every day for a week. On the first $2 \mathrm{~d}$ of each week (Monday and Tuesday), control data were collected, and were averaged to obtain the preinjection time point (Pre). On the day of muscimol injections (typically a Wednesday late-afternoon), a short block ( $\sim 20$ repetitions per stimulus) of behavioral data was obtained immediately after inactivation $(0 \mathrm{~h}$ time point). On the following Thursday morning, a long block ( $\sim 40$ repetitions per stimulus) of heading discrimination was performed $(12 \mathrm{~h})$, followed by another long block of trials $\sim 36$ $\mathrm{h}$ after inactivation $(36 \mathrm{~h})$ on Friday. Injection sites were chosen using criteria similar to those applied in previous MSTd inactivation experiments (see Materials and Methods; Gu et al., 2012).

MRI-based reconstruction of inactivation sites (see Materials and Methods) confirmed that muscimol injections were well targeted to the PIVC or the VIP area (Fig. 2, gray and black circles). The spatial extent of three example sets of injections, each set comprising two injections in each hemisphere, is illustrated in Figure 2 for Monkey J. Gray boundaries denote the VIP and anterior PIVC injections, whereas cyan boundaries indicate the posterior PIVC injections, and each boundary represents a flatmap projection of a spherical inactivation region with a radius of $2 \mathrm{~mm}$ (see Materials and Methods). Based on the flat-map projections for these example experiments, we estimate that we in- 


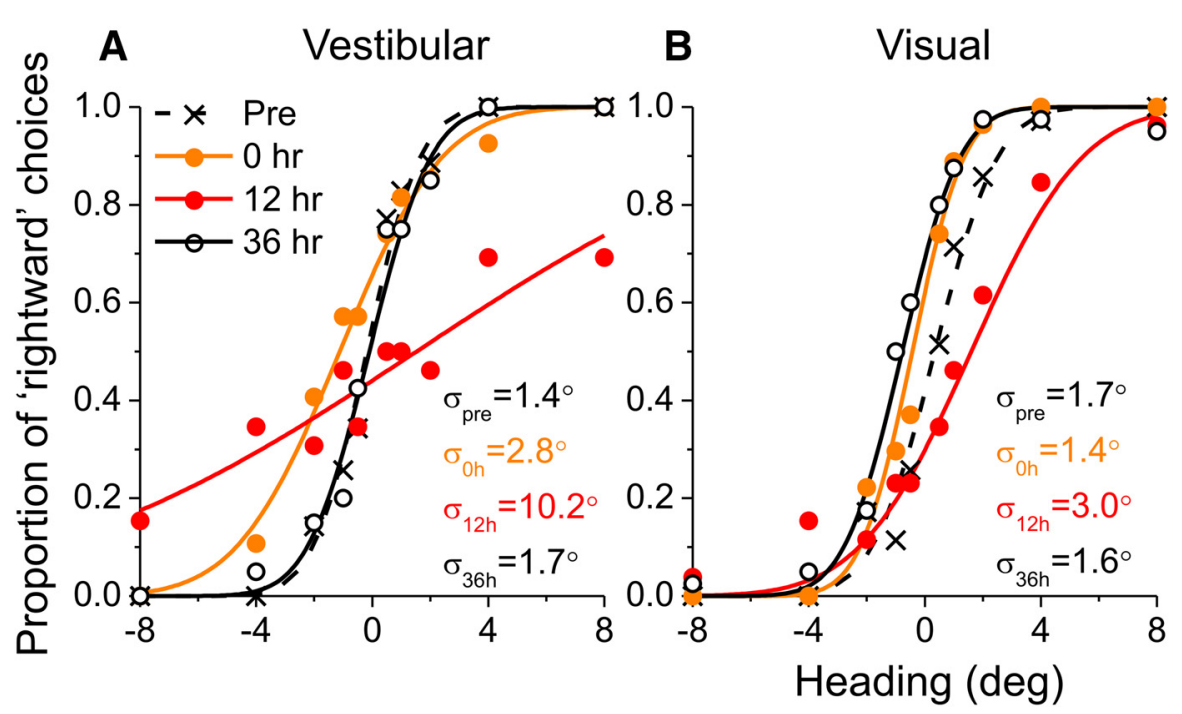

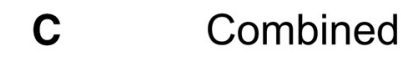

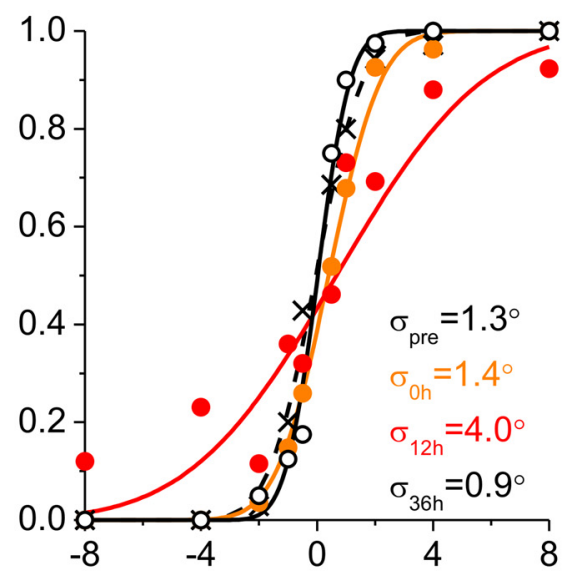

Figure 3. Data from an example inactivation session in which muscimol was injected into the anterior PIVC. Psychometric functions were collected at four time points: in the $2 \mathrm{~d}$ before muscimol injection (Pre, dashed curves and cross symbols), immediately after inactivation ( $0 \mathrm{~h}$, orange), $12 \mathrm{~h}$ after inactivation ( $12 \mathrm{~h}$, red), and $36 \mathrm{~h}$ after inactivation ( $36 \mathrm{~h}$, black solid curves and open symbols). $\boldsymbol{A}-\boldsymbol{C}$, Psychometric functions are shown for the visual $(\boldsymbol{A})$, vestibular $(\boldsymbol{B})$, and combined $(\boldsymbol{C})$ conditions. These data were collected following four bilateral injections of muscimol ( 2 in each hemisphere), with each injection having a volume of $2 \mu$ l and a concentration of $10 \mu \mathrm{g} / \mu \mathrm{l}$ (see Materials and Methods).

activated $16 \%$ of the anterior PIVC for the left hemisphere and $17 \%$ of the anterior PIVC for the right hemisphere, as well as $22 \%$ of the posterior PIVC for the left hemisphere, $25 \%$ of the posterior PIVC for the right hemisphere, $45 \%$ of the VIP area for the left hemisphere, and $37 \%$ of the VIP area for the right hemisphere. Reconstructions of all injections performed in Monkey J, for which inactivation experiments were performed in both the PIVC and the VIP area, indicate that we inactivated $19 \%$ of the PIVC on average (range: $12-30 \% ; N=16$ pairs of injections, pooling across anterior and posterior locations) and $36 \%$ of the VIP area on average (range: $25-50 \% ; N=16$ pairs of injections, one pair per hemisphere per experiment). The average percentage of the VIP area that was inactivated is significantly greater than the average for the PIVC $(p<$ 0.001, Wilcoxon rank sum test).

\section{Behavioral effects following PIVC inactivation}

Results from a typical inactivation experiment (two pairs of bilateral injections into the anterior PIVC) are illustrated in Figure 3. The largest effects were seen in the vestibular condition (Fig. $3 A$ ), for which inactivation of the PIVC increased the heading threshold from $1.4^{\circ}$ preinjection (dashed black curve) to $2.8^{\circ}$ immediately following the injections (orange). Twelve hours later, following additional spread of the drug effect, the heading threshold $\left(10.2^{\circ}\right)$ was elevated sevenfold (red), reflecting a pronounced behavioral impairment. Subsequently, performance recovered to preinjection levels $\left(1.7^{\circ}\right)$ at the $36 \mathrm{~h}$ time point (solid black curve). Inactivation also impaired the monkey's performance in the visual and combined conditions of this experiment (Fig. $3 B, C$ ), but these effects were substantially weaker compared with the vestibular condition.

Results from 14 PIVC inactivation experiments in two animals (Monkey J, $n=8$; MonkeyY, $n=6$, red symbols) are summarized in Figure $4 A$. Because the PIVC extends several millimeters along the anterior-posterior axis, we separated the PIVC data into two groups: anterior injections (Monkey J, $n=4$; Monkey Y, $n=3$, filled red symbols) and posterior injections (Monkey J, $n=4$; Monkey Y, $n=$ 3 , open red symbols). The anterior/posterior locations of injections were approximately matched across the two hemispheres (Table 1), such that data included in the anterior group involved anterior in- jections in both hemispheres, and likewise for posterior injections. Inactivation of the anterior PIVC typically had the largest effects on heading thresholds for the vestibular and combined conditions, whereas posterior inactivations of the PIVC (which likely encroach upon the VPS area, even though we did not target the VPS area) tended to have slightly larger effects in the visual condition. By comparison, inactivation of the MSTd area in Monkey J (Fig. 4A, black symbols; $n=8$; data from Gu et al., 2012) produced very weak effects in the vestibular condition but strong effects in the visual condition. Thus, the data from Monkey J reveal a clear difference in the pattern of inactivation results between the PIVC and the MSTd area.

Note that the pattern of PIVC inactivation results is somewhat different between Monkeys J and Y. Inactivation of the anterior PIVC in Monkey J selectively impacted vestibular heading judgements, whereas effects were more balanced across visual and vestibular conditions in Monkey Y. This difference likely arises from the fact that injections were, overall, more posterior and medial in Monkey Y than in Monkey J (Fig. 2; psychophysical thresholds for all experiments are summarized in Table 2). Consistent with this explanation, the largest inactivation effect in the vestibular condition for Monkey Y corresponded to the most anterior injection site.

To summarize the inactivation effects, data were pooled across experiments and animals for each stimulus condition. Figure $4 B$ shows normalized thresholds obtained by dividing the threshold measured at each time point by the corresponding preinjection (Pre) threshold. With the exception of visual inactivation effects for the posterior PIVC and visual/combined effects for MSTd, there were no significant interactions between animal identity and time relative to injection (Table 3; ANOVA), indicating that the effects were generally consistent across animals. Anterior PIVC injections led, on average, to an $85 \%$ increase in vestibular heading thresholds at $0 \mathrm{~h}$ postinjection $(p=0.037$, one-sample $t$ test, comparing the mean value to unity), and this effect increased to a fivefold threshold elevation at $12 \mathrm{~h}$ ( $p=$ 0.0085; Fig. 4B, left, solid red bars). Posterior PIVC injections increased vestibular heading thresholds by $46 \%$ on average at $0 \mathrm{~h}$ 


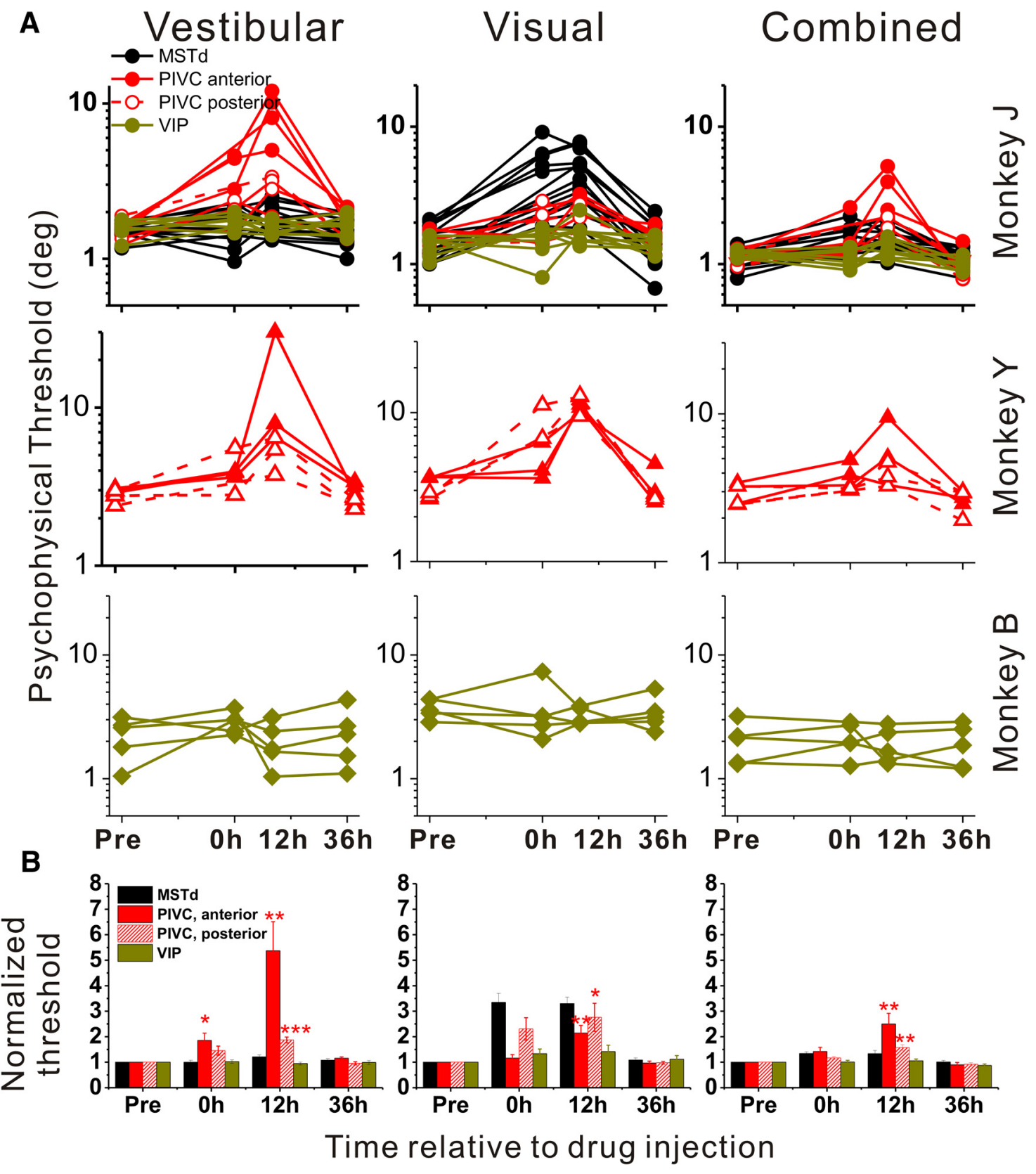

Figure 4. Summary of inactivation-induced increases in heading discrimination thresholds. A, Psychophysical thresholds of Monkeys J (upper row), $Y$ (middle row), and B (bottom row) are shown for experiments in which muscimol was injected bilaterally into the PIVC (red) or the VIP area (gold). Filled and open red symbols denote experiments involving injections into the anterior and posterior PIVC, respectively. For comparison, MSTd inactivation results are also shown for Monkey J (black; data from Gu et al., 2012). Data are shown separately for vestibular (left), visual (center), and combined (right) conditions. The abscissa in each panel marks the four different time points at which data were collected: Pre, $0 \mathrm{~h}, 12 \mathrm{~h}$, or $36 \mathrm{~h}$. B, Average normalized thresholds, computed by dividing the threshold at each time point by that from the preinjection (Pre) sessions. Solid and hatched red bars correspond to injections made in the anterior and posterior portions of the PIVC, respectively. Asterisks mark normalized thresholds significantly greater than unity $\left({ }^{*} p<0.05 ;{ }^{* *} p<0.01 ;{ }^{* *} p<0.001\right)$. Error bars: SEM. Black bars show MSTd inactivation data from three animals (replotted from Gu et al., 2012).

$(p=0.09)$ and by $87 \%$ at $12 \mathrm{~h}(p<0.001$; Fig. $4 B$, left, hatched red bars).

For comparison, Figure $4 B$ also shows normalized MSTd inactivation data from three animals (replotted from Gu et al., 2012). Overall, effects of PIVC inactivation on vestibular heading perception tended to be stronger than effects of MSTd inactivation; these differences were marginally significant at the $0 \mathrm{~h}$ time point (anterior PIVC vs MSTd area: $p=0.057$; posterior PIVC vs MSTd area: $p=0.064, t$ tests) and more highly significant at $12 \mathrm{~h}$ after inactivation (anterior: $p=0.01$; posterior: $p=0.002, t$ test).
Anterior and posterior PIVC inactivation also affected visual heading discrimination (Fig. 4A, $B$, middle column). After anterior PIVC injections, visual heading thresholds increased by only $16 \%$ at $0 \mathrm{~h}(p=0.34)$ but were elevated twofold at $12 \mathrm{~h}(p=$ $0.004)$. Following posterior PIVC inactivation, visual thresholds more than doubled on average at $0 \mathrm{~h}(p=0.07)$ and approximately tripled at $12 \mathrm{~h}(p=0.02)$. These visual threshold increases after posterior PIVC inactivation were comparable to those observed after MSTd inactivation (Gu et al., 2012; posterior PIVC vs MSTd area at $12 \mathrm{~h}, p=0.37, t$ test). In all cases, thresholds recovered to preinjection levels when tested at $36 \mathrm{~h}(p>0.05, t$ 
Table 2. Psychophysical thresholds for all inactivation experiments ${ }^{a}$

\begin{tabular}{|c|c|c|c|}
\hline \multirow[b]{2}{*}{ Area; Monkey } & \multicolumn{3}{|l|}{ Threshold } \\
\hline & $\begin{array}{l}\text { Vestibular: Pre/0 h/12 } \\
\mathrm{h} / 36 \mathrm{~h}\end{array}$ & $\begin{array}{l}\text { Visual: Pre/0 h/12 } \\
\mathrm{h} / 36 \mathrm{~h}\end{array}$ & $\begin{array}{l}\text { Combined: Pre/0 h/12 } \\
\text { h/36h }\end{array}$ \\
\hline \multirow[t]{8}{*}{ PIVC; J } & $1.58 / 2.79 / 10.19 / 1.68$ & $1.80 / 1.41 / 3.02 / 1.58$ & $1.14 / 1.41 / 3.98 / 0.88$ \\
\hline & $1.59 / 4.59 / 12.00 / 2.08$ & 1.48/2.19/3.23/1.68 & $1.18 / 2.58 / 5.15 / 0.78$ \\
\hline & 1.46/NaN/8.08/1.88 & $1.70 / \mathrm{NaN} / 2.97 / 1.62$ & $1.29 / \mathrm{NaN} / 2.20 / 1.01$ \\
\hline & $1.66 / 4.42 / 5.01 / 2.15$ & 1.78/1.56/2.20/1.96 & $1.09 / 1.19 / 2.48 / 1.46$ \\
\hline & 1.88/NaN/3.36/1.35 & $1.51 / \mathrm{NaN} / 2.32 / 1.31$ & $1.18 / \mathrm{NaN} / 2.21 / 1.08$ \\
\hline & $1.22 / 2.38 / 1.87 / 1.34$ & 1.20/2.88/2.18/1.44 & $1.02 / 1.21 / 1.44 / 1.06$ \\
\hline & 1.35/2.08/3.17/1.35 & 1.42/1.44/1.72/1.16 & 0.96/1.33/1.61/0.78 \\
\hline & $1.56 / 1.48 / 2.81 / 1.85$ & 1.36/2.28/2.73/1.33 & $1.07 / 1.15 / 1.84 / 0.84$ \\
\hline \multirow[t]{6}{*}{ PIVC;Y } & 3/3.95/7.90/3.39 & $3.7 / 3.62 / 11.34 / 2.82$ & 2.5/3.89/3.33/2.73 \\
\hline & 3.1/3.62/6.51/3.17 & $3.7 / 4.09 / 10.77 / 2.50$ & $3.25 / 3.31 / 5.1 / 2.48$ \\
\hline & 2.9/3.88/30.00/2.83 & $3.65 / 6.31 / 10 / 4.54$ & 3.45/4.9/9.45/3.02 \\
\hline & 2.4/NaN/3.74/2.42 & 2.64/NaN/9.43/2.87 & 2.47/NaN/3.28/1.93 \\
\hline & 2.78/2.80/5.39/2.29 & 2.72/11.22/12.78/2.73 & $2.5 / 3.07 / 4.74 / 3.0$ \\
\hline & 2.98/5.54/6.44/2.63 & 2.9/6.72/13/2.63 & $3.28 / 3.14 / 3.76 / 2.95$ \\
\hline \multirow[t]{8}{*}{ VIP; J } & 1.62/2.00/1.74/1.98 & 1.46/1.60/1.74/1.14 & $1.10 / 0.90 / 1.26 / 0.97$ \\
\hline & 1.66/1.89/1.74/1.68 & 1.49/1.47/1.74/1.53 & 1.23/0.95/1.18/1.16 \\
\hline & $1.78 / 1.87 / 1.42 / 1.86$ & 1.45/1.29/1.48/1.49 & $1.27 / 1.10 / 1.08 / 0.89$ \\
\hline & $1.52 / 1.77 / 1.46 / 1.40$ & $1.61 / 1.57 / 2.46 / 1.29$ & 1.25/1.32/1.22/0.97 \\
\hline & $1.74 / 1.60 / 1.82 / 1.35$ & 1.26/1.68/1.35/1.30 & $1.12 / 1.28 / 1.41 / 0.87$ \\
\hline & $1.21 / 1.26 / 1.75 / 1.70$ & 1.52/1.28/1.33/1.62 & 1.24/1.19/1.12/1.03 \\
\hline & 1.59/1.46/1.43/1.44 & 1.14/1.82/1.75/1.29 & 1.15/0.98/1.58/1.06 \\
\hline & $1.51 / 1.80 / 1.61 / 1.62$ & $1.02 / 1.83 / 1.47 / 1.29$ & 1.13/1.24/1.53/0.94 \\
\hline \multirow[t]{5}{*}{ VIP; B } & 4.37/7.32/3.72/2.39 & $1.80 / 2.26 / 1.66 / 1.53$ & 1.35/1.27/1.41/1.87/ \\
\hline & 4.39/3.18/3.87/5.32 & 2.71/3.73/1.04/1.10 & $1.32 / 1.94 / 1.65 / 1.24$ \\
\hline & $3.57 / 2.08 / 2.80 / 3.15$ & 1.05/2.98/1.74/2.28 & 2.20/2.70/1.33/1.21 \\
\hline & $3.38 / 3.21 / 2.82 / 2.90$ & 2.58/2.98/2.41/2.66 & $3.20 / 2.87 / 2.77 / 2.88$ \\
\hline & 2.87/2.70/2.85/3.46 & $3.14 / 2.41 / 3.12 / 4.34$ & 2.16/1.95/2.36/2.52 \\
\hline
\end{tabular}

aEach row corresponds to one experiment, as in Table 1. Columns show thresholds for the Vestibular, Visual, and Combined conditions. For each experiment and condition, thresholds (in degrees) are given for four time points: prior to injection (Pre), shortly following injection $(0 \mathrm{~h})$, the day following injection $(12 \mathrm{~h})$, and the second day following injection (36h). NaN denotes missing data corresponding to threshold estimates that were based on $<10$ stimulus repetitions.

Table 3. Summary of main effects and interaction effects from two-way ANOVA ${ }^{a}$

\begin{tabular}{lllll}
\hline Area & Condition & Animal & Time & Animal $*$ time \\
\hline Anterior PIVC & Vestibular & $p=0.465$ & $p<0.001$ & $p=0.930$ \\
& Visual & $p=0.446$ & $p=0.588$ & $p=0.222$ \\
& Combined & $p=0.197$ & $p<0.001$ & $p=0.295$ \\
Posterior PIVC & Vestibular & $p=0.816$ & $p<0.001$ & $p=0.983$ \\
& Visual & $p<0.001$ & $p<0.001$ & $p<0.001$ \\
& Combined & $p=0.402$ & $p<0.001$ & $p=0.538$ \\
VIP area & Vestibular & $p=0.277$ & $p=0.140$ & $p=0.507$ \\
& Visual & $p=0.028$ & $p=0.763$ & $p=0.242$ \\
& Combined & $p=0.363$ & $p=0.332$ & $p=0.151$ \\
MSTd area & Vestibular & $p=0.238$ & $p<0.001$ & $p=0.173$ \\
& Visual & $p=0.001$ & $p<0.001$ & $p=0.030$ \\
& Combined & $p<0.001$ & $p<0.001$ & $p<0.001$ \\
\hline
\end{tabular}

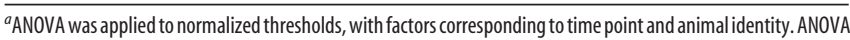
was performed separately for each brain area (anterior PIVC, posterior PIVC, VIP area, and MSTd area) and for each stimulus condition (Vestibular, Visual, and Combined). The rightmost three columns give $p$ values for the main effect of animal identity, the main effect of time point (relative to injection), and the interaction between animal and time point.

tests). Given the somewhat larger visual effects after posterior versus anterior PIVC injections, it is likely that the more posterior injections impinged upon the VPS area, which shows robust responses to optic flow (Chen et al., 2011b).

Heading thresholds in the combined condition showed modest effects of inactivation (Fig. $4 A, B$, right, red bars). At the $0 \mathrm{~h}$ time point, combined thresholds were not significantly different from preinjection values (anterior PIVC: $p=0.06$; posterior PIVC: $p=0.08, t$ tests). However, combined thresholds increased $>2$-fold at $12 \mathrm{~h}$ after injections into the anterior PIVC ( $p=0.01$, $t$ test), with substantially more modest effects (58\% elevation) following injections into the posterior PIVC ( $p=0.002)$. Compared with the MSTd area, inactivation effects in the combined condition at $0 \mathrm{~h}$ were not significantly different for both anterior $(p=0.59)$ and posterior $(p=0.29)$ PIVC injections, but inactivation effects in the PIVC were greater than those in the MSTd area at $12 \mathrm{~h}$ (anterior PIVC: $p=0.016$; posterior PIVC: $p=$ 0.018). Overall, the modest effects of PIVC inactivation in the combined condition may result from the fact that neither anterior nor posterior regions of the PIVC showed strong deficits in both the vestibular and visual conditions.

In summary, suppressing neural activity in the PIVC significantly and reversibly impaired heading discrimination, with anterior portions of the PIVC contributing more strongly to vestibular heading perception and posterior portions of the PIVC contributing more strongly to visual heading discrimination.

\section{Behavioral effects after VIP inactivation}

A total of 13 bilateral inactivation experiments were conducted in the VIP area of two monkeys (five experiments in Monkey B and eight experiments in Monkey J; Fig. 4A, $B$, gold symbols). Unlike the MSTd area and the PIVC, there was no significant change in heading thresholds following VIP inactivation for any of the stimulus conditions at any time point (Fig. $4 B$; vestibular: $p=$ 0.09 at $0 \mathrm{~h}, p=0.99$ at $12 \mathrm{~h}$; visual: $p=0.47$ at $0 \mathrm{~h}, p=0.15$ at $12 \mathrm{~h}$; combined: $p=0.86$ at $0 \mathrm{~h}, p=0.42$ at $12 \mathrm{~h} ; t$ tests comparing mean normalized thresholds to the unity value corresponding to preinjection data). Thus, in contrast to the PIVC and the MSTd area, inactivation of the VIP area led to no significant deficits in heading discrimination performance, despite use of the same behavioral task, experimental protocol, and data analyses.

\section{Discussion}

We have shown that reversible inactivation of the PIVC significantly impairs the precision of heading discrimination. Effects were strongest for the vestibular condition in the anterior PIVC, and strongest for the visual condition in the posterior PIVC. It is not surprising that bilateral inactivation of anterior or posterior portions of the PIVC impaired vestibular heading judgements, considering that most PIVC neurons show robust responses to inertial motion in darkness (Chen et al., 2010; Shinder and Newlands, 2014). Visual heading deficits following PIVC inactivation, on the other hand, might appear surprising because we have shown previously that PIVC neurons are not tuned for heading defined by optic flow (Chen et al., 2010). The fact that visual heading deficits were substantially larger following inactivation of posterior portions of the PIVC suggests strongly that our more posterior injections spread into the VPS area (even though we did not intentionally target the VPS area), which partly overlaps with the PIVC posteriorly and has robust responses to optic flow (Chen et al., 2011b). In this regard, it is interesting to note that human neuroimaging studies have identified a region of the posterior insular cortex (PIC) that appears to exhibit both visual and vestibular responses and lies adjacent to the human homolog of the PIVC. This PIC region may be a homolog of the VPS area (Frank et al., 2014; Billington and Smith, 2015).

We have shown previously that reversible chemical inactivation of the MSTd area increased psychophysical thresholds when heading judgments were based on either optic flow or vestibular cues, although the magnitude of the effects was substantially greater for visual heading discrimination (Gu et al., 2012). Behavioral deficits in the combined condition were intermediate between the single cue effects. Despite these deficits, animals were still able to combine visual and vestibular cues near optimally 
following muscimol injections into the MSTd area. Simulations showed that the overall pattern of results following MSTd inactivation is consistent with a mixture of contributions from the MSTd and other areas with vestibular-dominant heading tuning. Thus, the simulation results of Gu et al. (2012) suggested that inactivation of vestibular-dominant regions should also impact heading perception. The present results suggest strongly that the PIVC (and perhaps also its adjacent area, the VPS area) contributes to heading perception, in complement to the MSTd area.

In contrast to the clear visual and vestibular heading deficits observed after PIVC inactivation, we found no significant behavioral changes after VIP inactivation, even though we used the same experimental protocol, muscimol concentration and volume, behavioral task, and data analyses as in the MSTd and PIVC experiments. One of the animals (Monkey J) participated in all three experiments, indicating that differences in results across brain areas are unlikely to be attributable to subject differences. It also seems unlikely that the difference in results between the PIVC and the VIP area stems from the proportion of these areas that we inactivated. By reconstructing the putative regions of inactivation for all muscimol injections in Monkey J (Fig. 2; Materials and Methods), we estimate that we inactivated $19 \%$ of the total surface area of the PIVC, on average, and $36 \%$ of the surface area of the VIP area. These estimates assume that each injection spread over a radius of $2 \mathrm{~mm}$, which may be conservative, especially on the day following injection (see Materials and Methods). Critically, we found no effects of VIP inactivation despite the fact that we inactivated a significantly greater proportion of the VIP area than of the PIVC (owing mainly to greater average separation of pairs of injection sites in the VIP area; Table 1). This suggests strongly that our findings reflect differences in the functional contributions of the VIP area and the PIVC to heading perception.

It should be noted that we cannot rule out the possibility that behavioral deficits would result from inactivation of a larger fraction of the VIP area. We also cannot exclude the possibility that different geometries of the two sulci cause differential diffusion of muscimol in the PIVC and the VIP area. Although specific injections might have differentially affected the upper and lower layers of the VIP area, it is unlikely that our results reflect layer specificity given that none of the VIP injections caused deficits in behavior. Furthermore, no topographical organization of vestibular and optic flow properties has been previously identified in either the PIVC/VPS area or the VIP area (Chen et al., 2010, 2011a,b,c), although the possibility that such differences might exist cannot be excluded.

Our findings for the VIP area are especially surprising because responses of VIP neurons show the strongest correlations with perceptual decisions about heading that have been observed. Choice probabilities (CPs) quantify the extent to which choices can be predicted from single-unit activity, and average CPs for VIP neurons (Chen et al., 2013) are greater than those observed previously in the MSTd area (Gu et al., 2007, 2008) and the vestibular/cerebellar nuclei (Liu et al., 2013). To our knowledge, this is the first experimental demonstration that a brain area with robust choice-related activity in a particular task does not make a causal contribution to that task.

A previous study found that electrical microstimulation of the VIP area could bias visual heading perception during smooth pursuit eye movements but not during visual fixation (Zhang and Britten, 2011). Because we did not test heading discrimination during pursuit eye movements, it is possible that the VIP area selectively contributes to visual heading perception during eye movements. Overall, our findings lead us to conclude that either the VIP area provides a parallel and partially redundant pathway for heading perception, or that it does not participate in heading discrimination under the conditions of our task. Given the strong choice-related activity shown by VIP neurons, the VIP area might carry signals that reflect a decision variable for heading discrimination. However, it is unlikely that this decision variable is computed within the VIP area given the negative effects of inactivation observed here. Notably, a similar picture is beginning to emerge regarding the functions of the macaque LIP area (Yates et al., 2014) and the rat posterior parietal cortex (Erlich et al., 2015) in tasks involving perceptual decision making based on sensory evidence accumulation.

In summary, our reversible inactivation results strongly support the idea that the PIVC/VPS area is causally linked to heading judgments based on both vestibular and visual signals. In contrast, we find no evidence for a causal role of the VIP area in heading perception despite previous reports of strong choice-related activity. Together, these findings help to constrain the network of brain regions that are involved in self-motion perception.

\section{References}

Akbarian S, Grüsser OJ, Guldin WO (1994) Corticofugal connections between the cerebral cortex and brainstem vestibular nuclei in the macaque monkey. J Comp Neurol 339:421-437. CrossRef Medline

Allen TA, Narayanan NS, Kholodar-Smith DB, Zhao Y, Laubach M, Brown TH (2008) Imaging the spread of reversible brain inactivations using fluorescent muscimol. J Neurosci Methods 171:30-38. CrossRef Medline

Angelaki DE, Gu Y, DeAngelis GC (2011) Visual and vestibular cue integration for heading perception in extrastriate visual cortex. J Physiol 589: 825-833. CrossRef Medline

Arikan R, Blake NM, Erinjeri JP, Woolsey TA, Giraud L, Highstein SM (2002) A method to measure the effective spread of focally injected muscimol into the central nervous system with electrophysiology and light microscopy. J Neurosci Methods 118:51-57. CrossRef Medline

Billington J, Smith AT (2015) Neural mechanisms for discounting headroll-induced retinal motion. J Neurosci 35:4851-4856. CrossRef Medline

Bremmer F, Kubischik M, Pekel M, Lappe M, Hoffmann KP (1999) Linear vestibular self-motion signals in monkey medial superior temporal area. Ann N Y Acad Sci 871:272-281. CrossRef Medline

Bremmer F, Duhamel JR, Ben Hamed S, Graf W (2002a) Heading encoding in the macaque ventral intraparietal area (VIP). Eur J Neurosci 16: 1554-1568. CrossRef Medline

Bremmer F, Klam F, Duhamel JR, Ben Hamed S, Graf W (2002b) Visualvestibular interactive responses in the macaque ventral intraparietal area (VIP). Eur J Neurosci 16:1569-1586. CrossRef Medline

Bremmer F, Schlack A, Kaminiarz A, Hoffmann KP (2013) Encoding of movement in near extrapersonal space in primate area VIP. Front Behav Neurosci 7:8. CrossRef Medline

Britten KH (2008) Mechanisms of self-motion perception. Annu Rev Neurosci 31:389-410. CrossRef Medline

Britten KH, van Wezel RJ (1998) Electrical microstimulation of cortical area MST biases heading perception in monkeys. Nat Neurosci 1:59-63. CrossRef Medline

Britten KH, Van Wezel RJ (2002) Area MST and heading perception in macaque monkeys. Cereb Cortex 12:692-701. CrossRef Medline

Chen A, DeAngelis GC, Angelaki DE (2010) Macaque parieto-insular vestibular cortex: responses to self-motion and optic flow. J Neurosci 30: 3022-3042. CrossRef Medline

Chen A, DeAngelis GC, Angelaki DE (2011a) A comparison of vestibular spatiotemporal tuning in macaque parietoinsular vestibular cortex, ventral intraparietal area, and medial superior temporal area. J Neurosci 31:3082-3094. CrossRef Medline

Chen A, DeAngelis GC, Angelaki DE (2011b) Convergence of vestibular and visual self-motion signals in an area of the posterior sylvian fissure. J Neurosci 31:11617-11627. CrossRef Medline

Chen A, DeAngelis GC, Angelaki DE (2011c) Representation of vestibular and visual cues to self-motion in ventral intraparietal cortex. J Neurosci 31:12036-12052. CrossRef Medline 
Chen A, DeAngelis GC, Angelaki DE (2013) Functional specializations of the ventral intraparietal area for multisensory heading discrimination. J Neurosci 33:3567-3581. CrossRef Medline

Chen LL, Goffart L, Sparks DL (2001) A simple method for constructing microinjectrodes for reversible inactivation in behaving monkeys. J Neurosci Methods 107:81-85. CrossRef Medline

Chowdhury SA, DeAngelis GC (2008) Fine discrimination training alters the causal contribution of macaque area MT to depth perception. Neuron 60:367-377. CrossRef Medline

Chowdhury SA, Takahashi K, DeAngelis GC, Angelaki DE (2009) Does the middle temporal area carry vestibular signals related to self-motion? J Neurosci 29:12020-12030. CrossRef Medline

Colby CL, Duhamel JR, Goldberg ME (1993) Ventral intraparietal area of the macaque: anatomic location and visual response properties. J Neurophysiol 69:902-914. Medline

Dicke PW, Chakraborty S, Thier P (2008) Neuronal correlates of perceptual stability during eye movements. Eur J Neurosci 27:991-1002. CrossRef Medline

Duffy CJ (1998) MST neurons respond to optic flow and translational movement. J Neurophysiol 80:1816-1827. Medline

Edeline JM, Hars B, Hennevin E, Cotillon N (2002) Muscimol diffusion after intracerebral microinjections: a reevaluation based on electrophysiological and autoradiographic quantifications. Neurobiol Learn Mem 78: 100-124. CrossRef Medline

Erlich JC, Brunton BW, Duan CA, Hanks TD, Brody CD (2015) Distinct effects of prefrontal and parietal cortex inactivations on an accumulation of evidence task in the rat. Elife 4. CrossRef Medline

Fetsch CR, DeAngelis GC, Angelaki DE (2010) Visual-vestibular cue integration for heading perception: applications of optimal cue integration theory. Eur J Neurosci 31:1721-1729. CrossRef Medline

Frank SM, Baumann O, Mattingley JB, Greenlee MW (2014) Vestibular and visual responses in human posterior insular cortex. J Neurophysiol 112: 2481-2491. CrossRef Medline

Gibson JJ (1950) The perception of the visual world. Oxford: Houghton-Miffin.

Grüsser OJ, Pause M, Schreiter U (1990) Localization and responses of neurones in the parieto-insular vestibular cortex of awake monkeys (Macaca fascicularis). J Physiol 430:537-557. CrossRef Medline

Gu Y, Watkins PV, Angelaki DE, DeAngelis GC (2006) Visual and nonvisual contributions to three-dimensional heading selectivity in the medial superior temporal area. J Neurosci 26:73-85. CrossRef Medline

Gu Y, DeAngelis GC, Angelaki DE (2007) A functional link between area MSTd and heading perception based on vestibular signals. Nat Neurosci 10:1038-1047. CrossRef Medline

Gu Y, Angelaki DE, DeAngelis GC (2008) Neural correlates of multisensory cue integration in macaque MSTd. Nat Neurosci 11:1201-1210. CrossRef Medline

Gu Y, Fetsch CR, Adeyemo B, DeAngelis GC, Angelaki DE (2010) Decoding of MSTd population activity accounts for variations in the precision of heading perception. Neuron 66:596-609. CrossRef Medline

Gu Y, DeAngelis GC, Angelaki DE (2012) Causal links between dorsal medial superior temporal area neurons and multisensory heading perception. J Neurosci 32:2299-2313. CrossRef Medline

Guldin WO, Grüsser OJ (1998) Is there a vestibular cortex? Trends Neurosci 21:254-259. CrossRef Medline
Guldin WO, Akbarian S, Grüsser OJ (1992) Cortico-cortical connections and cytoarchitectonics of the primate vestibular cortex: a study in squirrel monkeys (Saimiri sciureus). J Comp Neurol 326:375-401. CrossRef Medline

Harris LR, Jenkin M, Zikovitz DC (2000) Visual and non-visual cues in the perception of linear self-motion. Exp Brain Res 135:12-21. CrossRef Medline

Jones EG, Burton H (1976) Areal differences in the laminar distribution of thalamic afferents in cortical fields of the insular, parietal and temporal regions of primates. J Comp Neurol 168:197-247. CrossRef Medline

Lewis JW, Van Essen DC (2000a) Mapping of architectonic subdivisions in the macaque monkey, with emphasis on parieto-occipital cortex. J Comp Neurol 428:79-111. CrossRef Medline

Lewis JW, Van Essen DC (2000b) Corticocortical connections of visual, sensorimotor, and multimodal processing areas in the parietal lobe of the macaque monkey. J Comp Neurol 428:112-137. CrossRef Medline

Liu S, Gu Y, DeAngelis GC, Angelaki DE (2013) Choice-related activity and correlated noise in subcortical vestibular neurons. Nat Neurosci 16: 89-97. CrossRef Medline

Liu Y, Yttri EA, Snyder LH (2010) Intention and attention: different functional roles for LIPd and LIPv. Nat Neurosci 13:495-500. CrossRef Medline

MacNeilage PR, Banks MS, DeAngelis GC, Angelaki DE (2010) Vestibular heading discrimination and sensitivity to linear acceleration in head and world coordinates. J Neurosci 30:9084-9094. CrossRef Medline

Ohmi M (1996) Egocentric perception through interaction among many sensory systems. Brain Res Cogn Brain Res 5:87-96. CrossRef Medline

Schaafsma SJ, Duysens J (1996) Neurons in the ventral intraparietal area of awake macaque monkey closely resemble neurons in the dorsal part of the medial superior temporal area in their responses to optic flow patterns. J Neurophysiol 76:4056-4068. Medline

Schlack A, Hoffmann KP, Bremmer F (2002) Interaction of linear vestibular and visual stimulation in the macaque ventral intraparietal area (VIP). Eur J Neurosci 16:1877-1886. CrossRef Medline

Shinder ME, Newlands SD (2014) Sensory convergence in the parietoinsular vestibular cortex. J Neurophysiol 111:2445-2464. CrossRef Medline

Telford L, Howard IP, Ohmi M (1995) Heading judgments during active and passive self-motion. Exp Brain Res 104:502-510. Medline

Van Essen DC, Drury HA, Dickson J, Harwell J, Hanlon D, Anderson CH (2001) An integrated software suite for surface-based analyses of cerebral cortex. J Am Med Inform Assoc 8:443-459. CrossRef Medline

Yang Y, Liu S, Chowdhury SA, DeAngelis GC, Angelaki DE (2011) Binocular disparity tuning and visual-vestibular congruency of multisensory neurons in macaque parietal cortex. J Neurosci 31:17905-17916. CrossRef Medline

Yates J, Katz L, Park IM, Pillow JW, Huk A (2014) Dissociated functional significance of choice-related activity across the primate dorsal stream. Abstract presented at Cosyne 2014, Salt Lake City, UT, March.

Zhang T, Britten KH (2011) Parietal area VIP causally influences heading perception during pursuit eye movements. J Neurosci 31:2569-2575. CrossRef Medline

Zhang T, Heuer HW, Britten KH (2004) Parietal area VIP neuronal responses to heading stimuli are encoded in head-centered coordinates. Neuron 42:993-1001. CrossRef Medline 